\title{
Chemoattraction of Echinostoma trivolvis (Trematoda) rediae TO LIPOPHILIC EXCRETORY-SECRETORY PRODUCTS AND THIN LAYER-CHROMATOGRAPHIC ANALYSIS OF REDIAL LIPIDS
}

\author{
REDDY A.*, FRAZER B.A.*, FRIED B.* \& SHERMA J.**
}

\section{Summary :}

High performance thin-layer chromatography (HPTLC) was used to analyze the lipophilic excretory-secretory (ES) products of

Echinostoma trivolvis rediae. These products were free sterols at a concentration of $0.83 \pm 0.03 \mu \mathrm{g} / 100 \mathrm{ml}$ and a lesser amount of free fatty acid that was not quantified. Preparative layer chromatography (PLC) was used to obtain the free sterol and free fatty acid fractions of redial ES products, and silica gel squares containing these lipids were tested against single rediae in a Petri dish bioassay. Rediae were significantly attracted to squares containing either free sterol or free fatty acid. HPTLC was also used to analyze the major lipid fractions in the redial bodies, which were free sterols, phosphatidylcholine $(\mathrm{PC})$, and phosphatidylethanolamine (PE). The major wet weight percentage \pm SE $(n=3)$ of free sterols was $2.59 \pm 0.16$ and for $P C$ and PE was $0.011 \pm 0.002$ and $0.010 \pm 0.002$, respectively.

KEY WORDS : Echinostoma trivolvis, Trematoda, redia, chemical attraction, thinlayer chromatography, neutral lipids, phospholipids.

MOTS CLÉS : Echinostoma trivolvis, trématode, rédie, chémoattraction, chromatographie en couche mince, lipides neutres, phospholipides.
Résumé : PRODUITS D'EXCRÉTION-SÉCRÉTION LIPIDIQUES DE RÉDIES D'ECHINOSTOMA TRIVOLVIS ET ANALYSE PAR CHROMATOGRAPHIE EN COUCHE MINCE

La chromatographie sur couche mince de haute performance (HPTLC) a été utilisée pour analyser les produits d'excrétionsécrétion (ES) lipidiques de rédies d'Echinostoma trivolvis. Ces produits sont d'une part des stérols libres à la concentration de $0,83 \pm 0,03 \mathrm{~g} / 100 \mathrm{ml}$, et d'autre part des acides gras libres dont la concentration n'a pas été déterminée. La chromatographie préparative (PTLC) a été employée pour séparer les fractions de stérols et d'acides gras libres à partir de produits ES, et des carrés de gels de silice contenant ces lipides ont été examinés contre des rédies isolées dans une boîte de Pétri selon la technique déjà employée. Les rédies sont significativement attirées par les carrés contenant soit des stérols libres, soit des acides gras libres. La HTPLC a été aussi utilisée pour analyser les fractions lipidiques majeures des rédies elles-mêmes. Les composés trouvés sont des stérols libres de la phosphatidylcholine (PC) et la phosphatidyléthanolamine (PE). Les pourcentages (en \% du poids humide) de ces composés \pm SE $(\mathrm{n}=3$ ) sont respectivement de $2,59 \pm 0,16$ pour les stérols, de 0,011 $\pm 0,002$ pour la $P C$ et de $0,010 \pm 0,002$ pour la PE.

\section{INTRODUCTION}

$\mathrm{R}$ elatively little work has been done on the lipid composition of the redial stages of digenetic trematodes (see references in Frayha \& Smith, 1983; Fried \& Sherma, 1990), and most of the studies are based on the analyses of lipids in rediae contained within the digestive gland gonad complex (DGG) of the snail host (Fried et al., 1990; Beers et al., 1995). A recent study in our laboratory using daughter rediae of the ubiquitous North American digenetic trematode Echinostoma trivolvis (see review in Huffman \& Fried, 1990) showed that these rediae are attracted to each other in vitro and that lipids released from them are chemoattractants (Reddy \& Fried, 1996). The purpose of this study was to identify the lipid classes released by rediae of $E$. trivolvis into a bioassay medium and

\footnotetext{
* Department of Biology and

** Department of Chemistry, Lafayette College, Easton, PA 18042, USA. Correspondence: Bernard Fried. Tel.: 610-250-5463 - Fax: 610-2506557.
}

to determine which lipids are chemoattractive. Additionally, analyses were done on the lipids in the redial bodies of this echinostome.

\section{MATERIALS AND METHODS}

\section{OBTAINING REDIAE AND SAMPLE PREPARATION}

H elisoma trivolvis snails naturally infected with daughter rediae of Echinostoma trivolvis were obtained from a farm pond in Northampton County, PA, USA. Rediae were dissected from the DGG of snails and rinsed in several changes of Locke's solution prior to use. The morphology of the redia of this species was described by Fried \& Awatramani (1992).

To obtain redial excretory-secretory (ES) products, 500 rediae were placed in $2 \mathrm{ml}$ of Locke's 1:1 solution in a $10 \times 75 \mathrm{~mm}$ disposable glass culture tube (BectonDickinson Co., Rutherford, NJ, USA) at $22{ }^{\circ} \mathrm{C}$ for $1 \mathrm{~h}$. The redial-free incubate $(2 \mathrm{ml})$ was removed by pipet and extracted in $3 \mathrm{ml}$ of chloroform-methanol (2:1). 
The extract was then filtered through glass wool and treated with the Folch wash $(0.88 \% \mathrm{KCl})$ to obtain a hydrophilic (top) and a lipophilic (bottom) phase. The hydrophilic layer was removed and discarded, and the lipophilic layer was used for the behavior and thinlayer chromatography (TLC) studies described herein. A total of 2,500 rediae were used in five trials to obtain the ES products needed to complete these studies.

TLC analysis of redial bodies was done by extracting 500 rediae (about $60 \mathrm{mg}$ wet weight) in $3 \mathrm{ml}$ of chloroform-methanol $(2: 1)$ and then preparing the lipid extract essentially as described for the ES products. Five trials, each with 500 rediae, were used for the HPTLC analyses of redial bodies.

Identification of lipids in ES products and redial bodies was done by high performance thin-layer chromatography (HPTLC) as described in the last section of the "Materials and methods". After it was determined that the redial ES products were free sterols and free fatty acids, preparative layer chromatography (PLC) was used to isolate these fractions from the silica gel plates. To do PLC, from 100 to $200 \mu \mathrm{l}$ of the ES lipophilic extract was streaked on the origin of a $20 \times 20 \mathrm{~cm}$ silica gel sheet (Bakerflex IB2, J.T. Baker Chemical Co., Phillipsburg, NJ, USA) in a narrow, $10 \mathrm{~cm}$ band, $5 \mathrm{~cm}$ from each edge as described in Fried et al. (1980). Ten $\mu \mathrm{l}$ of sample and $5 \mu \mathrm{l}$ of neutral lipid standard (see last section of the "Materials and methods ") were spotted on the origin within $5 \mathrm{~cm}$ of each edge. The sheet was developed in petroleum ether-diethyl etheracetic acid (80:20:1), and each $5 \times 20 \mathrm{~cm}$ edge was cut and removed from the center $10 \times 20 \mathrm{~cm}$ piece. The edges were sprayed with $5 \%$ ethanolic phosphomolybdic acid (PMA) and heated at $115^{\circ} \mathrm{C}$ to produce blue lipid zones on a light yellow background, and then matched against the center piece of the plate (see Fig. 12.2 on page 192 of Fried \& Sherma, 1986). PLC showed two neutral lipid bands in the ES products, a free sterol band at $\mathrm{R}_{f}=0.27-0.32$, and a free fatty acid band at $\mathrm{R}_{f}=0.50-0.55$. These bands (about $1 \mathrm{~cm}$ wide) were cut from the center portion of the silica gel and prepared as $0.5 \mathrm{~cm}^{2}$ squares for use in the behavior studies (see next section) along with a lipid-free band at $\mathrm{R}_{f}=0.75-0.80$.

\section{Chemoattraction of Rediae TO SILICA GEL SQUARES}

To observe redial chemoattraction toward the free sterol and free fatty acid zones removed from the silica gel sheets, attraction of a single redia to a silica gel square was tested in a $3.5 \mathrm{~cm}$ Petri dish bioassay containing an agar substratum and a Locke's overlay (see Reddy \& Fried, 1996). The dish was divided into three approximately equal areas of about $4.2 \mathrm{~mm}^{2}$. One area (A) was designated attractive and received a piece of $0.5 \mathrm{~cm}^{2}$ silica gel at its edge containing either the free sterol or free fatty acid fraction. A blank piece of $0.5 \mathrm{~cm}^{2}$ silica gel was placed at the opposite end of the dish, designated the non-attractive area (C). The central area (B) was considered neutral, and a single redia was placed in it equidistant between the two silica gel squares. Squares were placed in the dish 10 min prior to inoculating a single redia into area $\mathrm{B}$. Rediae that moved into area A were scored as being attracted. Redial attraction to the free sterol square was tested 12 times, with observations made at $0,0.25,0.50$, $1.0,1.25,1.5,2.0$, and $4.0 \mathrm{~h}$. A similar protocol was used to test the free fatty acid squares. Chemoattraction was defined as the percent of rediae in the attractive area at each time.

\section{HPTLC ANALYSIS OF REDIAL EXCRETORY/SECRETORY (ES) PRODUCTS AND REDIAL BODIES}

To determine neutral lipids in the ES products and in redial bodies, HPTLC was performed as described by Masterson et al. (1993) using Whatman (Clifton, NJ, USA) LHP-KDF high performance $10 \times 20 \mathrm{~cm}$ channeled, preadsorbent silica gel plates. The standard used was the neutral lipid standard 18-4A (Matreya, Pleasant Gap, PA, USA), which contained $0.20 \mu \mathrm{g} / \mu \mathrm{l}$ each of cholesteryl oleate, methyl oleate, triolein, oleic acid, and cholesterol. The standard and reconstituted sample solutions (the lipophilic extract of 500 rediae was evaporated to dryness and reconstituted with $100 \mu 1$ of chloroform-methanol, 2:1) were spotted in 2.0, 4.0, 8.0, and $16.0 \mu \mathrm{l}$ aliquots on the same plate using a $25 \mu \mathrm{l}$ Drummond (Broomall, PA, USA) digital microdispenser. Plates were developed with petroleum ether-diethyl ether-acetic acid (80:20:2) to a distance of $7.5 \mathrm{~cm}$ past the preadsorbent-silica gel interface in a glass, paper-lined Camag (Wilmington, NC, USA) twin-trough HPTLC chamber. The plates were dried using a hair dryer, and lipids were detected by spraying with PMA. Sample and standard zones of free sterols were scanned using a Shimadzu CS-930 densitometer operated in the single beam, single wavelength mode at $700 \mathrm{~nm}$. Calculation of sterol percentages based on the scan areas of the four standards and the single sample zone with an intensity closest to the two middle standards was performed as described by Higgs et al. (1990).

Phospholipid analysis was done as described in Perez et al. (1994). The standard used was Matreya polar lipid mix No. 1127 , containing $0.25 \mathrm{mg} / \mathrm{ml}$ each of cholesterol, phosphatidylethanolamine, phosphatidylcholine, and lysophosphatidylcholine. The silica gel HPTLC plates were spotted and developed with chloroformmethanol-water (65:25:4) as described above for neutral lipids. Phospholipids were detected as black spots 
on a white background by spraying the dried plate with a $10 \%$ solution of cupric sulfate in $8 \%$ phosphoric acid, and heating in an oven at $160^{\circ} \mathrm{C}$ for $10 \mathrm{~min}$ Phospholipid zones were scanned at $370 \mathrm{~nm}$.

\section{RESULTS}

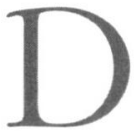

aughter rediae of Echinostoma trivolvis were significantly attracted to silica gel squares impregnated with the neutral lipid standard.

\section{LIPIDS IN ES PRODUCTS AND REDIAL BODIES}

Daughter rediae of E. trivolvis released free sterols $\left(\mathrm{R}_{f}=0.23\right)$ and free fatty acids $\left(\mathrm{R}_{f}=0.31\right)$ but not phospholipids into the medium. Natural pigments, i.e., carotenoids, which occur in the redial bodies (see Fried et al., 1993), were not released into the medium. The free sterols released into the medium were quantified in three separate trials against the cholesterol standard based on the fact that greater than $95 \%$ of E. trivolvis free sterol is cholesterol (see Chitwood et al., 1985) and were found to be present at a concentration of 0.83 $\pm 0.03 \mu \mathrm{g} / 100 \mathrm{ml}$. The free fatty acids released into the medium were detected but not quantified. The free fatty acids were detected as trace amounts but could not be quantified because the scan area of the $16.0 \mu \mathrm{l}$ sample free fatty acid zone was below the scan area of the $2.0 \mu \mathrm{l}$ standard zone, i.e., no sample zone was bracketed between the standards using the 500 redial sample.

The most abundant neutral lipid fraction in the redial bodies was free sterol $\left(R_{f}=0.23\right)$, along with lesser amounts of triacylglycerols $\left(\mathrm{R}_{f}=0.65\right)$, free fatty acids $\left(\mathrm{R}_{f}=0.31\right)$ and sterol esters $\left(\mathrm{R}_{f}=0.89\right)$. The mean wet weight percentage \pm SE of free sterols in the redial bodies $(n=3)$ was $2.59 \pm 0.16$. The other neutral lipids were not quantified because their zones could not be clearly distinguished from pigment bands that reacted with PMA after the plates were heated.

Phospholipids detected in the redial bodies were phosphatidylcholine ( $\left.\mathrm{PC} ; \mathrm{R}_{f}=0.36\right)$ and phosphatidylethanolamine $\left(\mathrm{PE} ; \mathrm{R}_{f}=0.54\right)$. The mean wet weight percentage $(n=3)$ of PC and PE was $0.011 \pm 0.002$ and $0.010 \pm 0.002$, respectively.

\section{ATTRACTION OF REDIAE TO FREE STEROLS} AND FREE FATTY ACIDS ON THE SILICA GEL SQUARES

Preliminary studies showed that single rediae did not migrate out of area B in the absence of a stimulus. Therefore, if areas $\mathrm{A}$ and $\mathrm{C}$ contained blank silica gel squares, the percent attraction was always zero. In the presence of silica gel squares with either free sterol or free fatty acid fractions, rediae either migrated into area $\mathrm{A}$ or remained in area $\mathrm{B}$, but never moved into area $\mathrm{C}$. The results of the chemoattraction studies are summarized in Table I and show that attraction became greater as a function of time when rediae were tested against both free sterols and free fatty acids. Student's $t$-test $(\mathrm{P}<0.05$ being considered significant $)$ showed that redial attraction was significantly greater to the free fatty acid fraction versus the free sterol fraction at 15 , 30,45 , and $60 \mathrm{~min}$. Beyond that time there was no significant difference in the fatty acid versus free sterol fraction.

Table I. - Chemoattraction of single rediae of E. trivolvis to silica gel squares containing free fatty acid or free sterol excretory-secretory redial products

Percentage of rediae $\pm S E$ in area $A^{*}$

$\begin{array}{ccc}\text { Time in min } & \text { Free fatty acids } & \text { Free Sterols } \\ 0 & 0.0+0 & 0.0+0 \\ 15 & 17 \pm 1 & 8.3 \pm 0.8 \\ 30 & 33 \pm 2 & 25 \pm 2 \\ 45 & 67 \pm 4 & 42 \pm 3 \\ 60 & 75 \pm 6 & 42 \pm 3 \\ 90 & 83 \pm 4 & 75 \pm 5 \\ 120 & 83 \pm 4 & 75 \pm 5 \\ 240 & 92 \pm 6 & 83 \pm 5\end{array}$

Rediae not in area A were in area B; rediae never migrated into area $\mathrm{C}$.

The experimental set up of the Petri dish bioassay was as follows: area A was designated attractive and received a $0.5 \mathrm{~cm}^{2}$ piece of silica gel containing either the free sterol or fatty acid fraction; area $\mathrm{C}$ was at the opposite end of the dish and was designated the nonattractive area and received a blank piece of $0.5 \mathrm{~cm}^{2}$ silica gel ; the central area (B) was considered neutral, and a single redia was placed in it equidistant between the two silica gel squares.

\section{DISCUSSION}

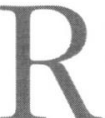
eddy and Fried (1996) showed that lipophilic, but not hydrophilic, ES products were involved in chemoattraction of echinostome rediae in vitro. The chemical classes of lipids were not identified in that study. The present study has determined that the lipophilic ES products of E. trivolvis rediae are free sterols and free fatty acids, and that both of these lipid classes can produce significant intraspecific redial attraction in vitro. Free sterols have been implicated as chemical attractants for both hermaphroditic and dioecious adult trematodes (see reviews in Fried, 1986 and Haseeb \& Fried, 1988) and free fatty acids in vertebrate skin as chemoattractants for avian and mammalian schistosome cercariae (Haas, 1992).

Quantitative analysis of lipids in echinostome rediae devoid of host DGG are not available, and this study provides such information for the first time for free sterols and phosphatidylcholine and phosphatidyletha- 
nolamine. Knowledge of the amounts of free sterols and phospholipids in the redial stages of trematodes may be useful for a better understanding of the physiology and biochemistry of this poorly understood larval stage.

\section{ACKNOWLEDGEMENT}

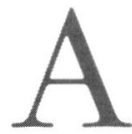

$\mathrm{R}$ was supported by a Merck/AAAS Undergraduate Science Research Program Award recived by the Chemistry and Biology Departments of Lafayette College.

\section{REFERENCES}

Beers K., Fried B., Fujino T. \& Sherma J. Effects of diet on the lipid composition of the digestive gland-gonad complex of Biomphalaria glabrata (Gastropoda) infected with larval Echinostoma caproni (Trematoda). Comparative Biochemistry and Physiology, 1995, 110B, 729-737.

Chitwood D.J., Lusby W.H. \& Fried B. Sterols of Echinostoma revolutum (Trematoda) adults. Journal of Parasitology, 1985, 71, 846-847.

FraYha G.J. \& SMYTH J.D. Lipid metabolism in parasitic helminths. Advances in Parasitology, 1983, 22, 309-387.

FRIED B. Chemical communication in hemaphroditic digenetic trematodes. Journal of Chemical Ecology, 1986, 12, 16591677.

Fried B. \& Awatramani R. Light and scanning electron microscopical observations of the daughter rediae of Echinostoma trivolvis (Trematoda). Parasitology Research, 1992, 78, 257-259.

Fried B., Beers K. \& Sherma J. Thin-layer chromatographic analysis of beta carotene and lutein in Echinostoma trivolvis (Trematoda) rediae. Journal of Parasitology, 1993, 79, 113-114.

Fried B., Holender, E.S., Shetty P.H. \& Sherma J. Effects of Echinostoma trivolvis (Trematoda) infection on neutral lipids, sterols, and carotenoids in Helisoma trivolvis (Gastropoda). Comparative Biochemistry and Physiology, 1990, $97 B, 601-604$.

Fried B. \& Sherma J. Thin layer chromatography of lipids found in snails (Gastropoda: Mollusca). Journal of Planar Chromatography-Modern TLC, 1990, 3, 290-299.

Fried B. \& Sherma J. Thin-layer Chromatography: Techniques and Applications. $2^{\text {nd }}$ Ed., 1986, Marcel Dekker, Inc., New York, 394 p.

Fried B., Tancer R.B. \& Fleming S.J. In vitro pairing of Echinostoma revolutum (Trematoda) metacercariae and adults and characterization of worm products involved in chemoattraction. Journal of Parasitology, 1980, 66, 1014-1018.

HAAS W. Physiological analysis of cercarial behavior. Journal of Parasitology, 1992, 78, 243-255.

Haseeb M.A. \& Fried B. Chemical communication in helminths. Advances in Parasitology 1988, 27, 169-207.
Higgs M.H., Sherma J. \& Fried B. Neutral lipids in the digestive gland-gonad complex of Biomphalaria glabrata snails fed lettuce versus hen's egg yolk determined by quantitative thin layer chromatography-densitometry. Journal of Planar Chromatography-Modern TLC, 1990, 3, 38-41.

HufFman J.E. \& Fried B. Echinostoma and echinostomiasis. Advances in Parasitology, 1990, 29, 215-269.

Masterson C., Fried B. \& Sherma J. High-performance thinlayer chromatographic analysis of neutral lipids in Biomphalaria glabrata (Gastropoda) fed egg yolk-lettuce versus lettuce-Tetramin diets. Microchemical Journal 1993, 47, 134-139.

Perez M., Fried B. \& Sherma J. Comparison of mobile phases and HPTLC qualitative and quantitative analysis, on preadsorbent silica gel plates, of phospholipids in Biomphalaria glabrata (Gastropoda) infected with Echinostoma caproni (Trematoda). Journal of Planar Chromatography-Modern TLC, 1994, 7, 340-343.

REDDY A. \& Fried B. In vitro studies on intraspecific and interspecific chemical attraction in daughter rediae of Echinostoma trivolvis and E. caproni. International Journal for Parasitology, 1996, 26, 1081-1085.

Reçu le 17 août 1996 Accepté le 29 novembre 1996 